\title{
A Randomized Comparison of Rectal Misoprostol and Intramuscular Oxytocin for Prevention of Postpartum Hemorrhage
}

\author{
Zareena Hassan, Shashi Gupta \\ Department of Gynaecology \& Obstetrics, \\ Govt. Medical College, Srinagar
}

\begin{abstract}
Objective: To compare the safety and effectiveness of rectal misoprostol and intramuscular oxytocin in prevention of postpartum hemorrhage (PPH).

Methods: A prospective study was conducted in 400 women undergoing uncomplicated vaginal delivery between 34-42 weeks of gestation divided in two groups. Group A with 200 patients were given 400mcg of misoprostol as rectal enema and Group B with 200 patients were given $101 \mathrm{U}$ of oxytocin intramuscularly after delivery of baby and before cord clamping. Results were compared in both the groups in terms of safety and effectiveness.

Results: In both the groups, third stage was uncomplicated. No significant difference was observed in mean hemoglobin concentration ( $P=0.74,0.92)$ before and after delivery. No significant difference was seen in mean hematocrit value $(P=0.63,0.08)$ before and after delivery. No statistical significant difference was observed in mean systolic $(P=0.62,0.53)$ and mean diastolic $(P=0.83,0.71)$ before and after delivery. Mean temperature before and after delivery in both groups showed statistical significant difference $(P=.068$, $0.0001)$. Statistical significant difference $(P=0.0001)$ was observed in side effects in both the groups. Shivering was the main side effect in misoprostol groups.
\end{abstract}

Conclusion: Rectal administration of misoprostol is better and safe alternative for prevention of PPH than oxytocin.

Keywords: Oxytocin, postpartum hemorrhage, rectal misoprostol.

\section{Introduction}

Postpartum hemorrhage is the major cause of maternal morbidity and mortality in developing as well as developed countries. ${ }^{1}$ In the developing world, including India, postpartum hemorrhage (PPH) accounts for up to half of all maternal deaths. Even in developed countries, life threatening PPH occurs in about 1 in 1000 deliveries. Incidence of PPH is estimated $2-11 \%$ of deliveries, but if objective assessment of blood loss is made, the incidence may rise up to $20 \% .{ }^{2}$ In rural communities, the lack of access to skilled birth attendant who are able to administer parenteral oxytocic agents, the high incidence of anemia in pregnancy, the lack of availability of safe blood transfusion services and the lack of refrigeration to store oxytocic agents worsens the outcome of postpartum hemorrhage. The prophylactic use of oxytocics in the third stage of labour has been shown to significantly reduce the risk of postpartum hemorrhage from $10 \%$ to $6 \%{ }^{3}$ Side effects of conventional oxytocic drugs range from nausea, vomiting and hypertension to postpartum eclampsia, intracerebral hemorrhage, myocardial infarction, cardiac arrest, pulmonary edema and inadvertent administration of the oxytocic agent can cause neonatal convulsions. ${ }^{4}$ Active management of the third stage of labour (AMTSL) is a collection of therapies and treatments (uterotonic drugs, controlled cord traction and fundal massage) thought to be effective at reducing maternal blood loss and morbidity. ${ }^{5}$

Uterotonics, primarily oxytocin, in hospital settings are safe and effective for prophylaxis and treatment of atonic postpartum hemorrhage. ${ }^{6}$ Similar is the case with

\section{Correspondence}

Dr. Zareena Hassan, MD

Registrar, Department of Gynaecology \& Obstetrics,

Govt. Medical College, Srinagar

Email:drwani22@gmail.com Cell:+91-9419148704 
methylergometrine which can cause, if administered intravenously, severe hypertension in women with preeclampsia. These oxytocics have to be administered parenterally, are not stable at room temperature and must be protected from light. Because of its uterotonic effect, parenteral administered prostaglandin $\mathrm{F}_{2}$ a has also been used for the treatment of PPH, but it is expensive, causes nausea and vomiting, and therefore is not suitable for routine prophylaxis.

El-Rafey et al (1996) ${ }^{7}$ were the first to report on the usefulness of misoprostol in the active management of the third stage of labour. They found that misoprostol, an inexpensive drug needing no refrigeration and easily absorbed, via gastrointestinal tract, could be a good alternative to the traditional oxytocic agents. Misoprostol was then studied for oral and rectal administration during third stage of labour, and was shown to cause nausea, vomiting, fever and chills, but these adverse effects were dose related. ${ }^{8}$

The purpose of our study was to compare the efficacy and side effects of rectal misoprostol and intramuscular oxytocin in preventing postpartum hemorrhage.

\section{Methods}

From December 2005 to November 2006, 400 women undergoing uncomplicated vaginal delivery between 34 weeks to 42 weeks of gestation in the Department of Obstetrics and Gynaecology, SMGS Hospital, Government Medical College Jammu were selected for this study. Selected cases were divided in two groups. Group A comprised of 200 patients who were given $400 \mathrm{mcg}$ of misoprostol ( 2 tablets of $200 \mathrm{mcg}$ ) dissolved in $5 \mathrm{ml}$ of saline and placed in a sterile disposable syringe administered as microenema. Group B comprised of 200 patients who were given $10 \mathrm{IU}$ of oxytocin $(2 \mathrm{ml}$, each $\mathrm{ml}$ contains $5 \mathrm{IU}$ ) prepared in disposable syringe administered intramuscularly.

Women with less than 34 weeks or $>42$ weeks of gestation or under going an induction and/or augmentation of labour with any drug or with medical complications like heart disease, chronic hypertension, renal disease, bronchial asthma and history of hypersensitivity to drug were excluded. Before undertaking the procedure, a detailed history was recorded. Complete general physical, systemic and local examination was done and a written consent was obtained from the patient.

After routine investigations, vitals as blood pressure, temperature and pulse were measured and a blood sample for hemoglobin and hematocrit was taken 30 minutes before vaginal delivery. After the vaginal delivery and before cord clamping, the patients selected were given either rectal misoprostol, or intramuscular oxytocin. Observations included measurement of blood loss after delivery of fetus, duration of third stage, changes in temperature and blood pressure and occurrence of side effects like shivering, vomiting, diarrhea or fever. Occurrence of retained placenta, need for additional oxytocic drugs and requisition and/or administration of blood were also documented. Blood loss was measured by placing a metallic collector under woman's buttocks immediately after delivery and maintaining it during the third stage till patient was taken from delivery room. After 48 hours of delivery, second blood sample for hemoglobin and hematocrit was collected. Statistical analysis was performed and the results were compared between the two groups.

\section{Statistical Analysis}

Data analysed with the help of computer software Microsoft Excel and Epi-info for Windows. For quantitative variables, mean and standard deviation was calculated. Chi-square and pooled ' $t$ ' test were used to evaluate statistically. Significant difference between the two groups at $p$ value of $<0.05$ was considered as statistical significant.

\section{Results}

During our study, majority of patients in both groups were in age group 21-25 years and belonged to social class III. 54\% of patients in group A and 51\% in group $\mathrm{B}$ were nullipara. $77 \%$ of patients in group $\mathrm{A}$ and $88 \%$ in group B were with gestational age of 38-40 weeks.

$88 \%$ of group A and $89.5 \%$ of group B had normal delivery with episiotomy, $40 \%$ of misoprostol group had duration of third stage of labour of 10-15 minutes as $37 \%$ of oxytocin group. Mean duration of third stage was $12.96( \pm 4.33)$ minutes in group A and $13.51( \pm 4.53)$ minutes in group $B$ with no statistical significant difference $(P=0.22)$. Both drugs were equally effective as neither the groups showed prolonged third stage of labour.

$65 \%$ in group A and $62.5 \%$ in group B had blood loss between 100-200ml. Mean blood loss in group A was $128.10( \pm 41.88) \mathrm{ml}$ and in group B was $123.92( \pm 37.07) \mathrm{ml}$ with no statistical significant difference $(\mathrm{P}=0.292)$. No patient had postpartum hemorrhage in both the groups as defined clinically as well as quantitatively. The mean changes in hemoglobin and hematocrit from before to 48 hours postpartum were statistically not significant in both groups (Table 1). No statistical significant difference was observed in mean blood pressure changes (Table 2). [Before (systolic, $\mathrm{P}=0.62$, diastolic, $\mathrm{P}=0.83$ ) and 60 minutes after delivery (systolic, $\mathrm{P}=$ 0.83 ; diastolic, $\mathrm{P}=0.71)]$. There was statistical significant difference between group $\mathrm{A}$ and group $\mathrm{B}$ with respect to mean temperature 30 minutes before $(\mathrm{P}=0.068)$ and 60 minutes postpartum $(\mathrm{P}=0.0001)$ (Table 
Table 1. Mean Hemoglobin and Hematocrit Before and 48 Hours After Delivery

\begin{tabular}{|c|c|c|c|c|}
\hline & & Group A & Group B & $\mathbf{P}$ \\
\hline \multicolumn{5}{|c|}{ Hemoglobin (gm\%) } \\
\hline \multirow{2}{*}{$\overline{\mathrm{X}}+\mathrm{SD}$} & Before Delivery & $9.80( \pm 0.542)$ & $9.82( \pm 0.579)$ & 0.74 \\
\hline & After Delivery & $9.39( \pm 0.454)$ & $9.38( \pm 0.494)$ & 0.92 \\
\hline \multicolumn{5}{|c|}{ Hematocrit (\%) } \\
\hline \multirow{2}{*}{$\bar{X}+\mathrm{SD}$} & Before Delivery & $33.88( \pm 1.53)$ & $33.95( \pm 1.56)$ & 0.63 \\
\hline & After Delivery & $32.55( \pm 1.70)$ & $32.82( \pm 1.36)$ & 0.08 \\
\hline
\end{tabular}

Table 2. Mean Blood Pressure and Temperature 30 Minutes Before and 60 Minutes Postpartum

\begin{tabular}{|c|c|c|c|c|}
\hline \multicolumn{5}{|c|}{ Temperature $\left.{ }^{\circ} \mathrm{C}\right)$} \\
\hline \multirow{2}{*}{$\bar{X} \pm \mathrm{SD}$} & Before Delivery & $36.88( \pm 0.11)$ & $36.86( \pm 0.10)$ & 0.068 \\
\hline & After Delivery & $37.27(+0.52)$ & $36.93(+0.19)$ & 0.0001 \\
\hline \multicolumn{5}{|c|}{ Blood Pressure $(\mathrm{mmHg})$} \\
\hline \multirow{4}{*}{$\bar{X}+\mathrm{SD}$} & $\begin{array}{c}\text { Systolic Before } \\
\text { Delivery }\end{array}$ & $122.27( \pm 7.90)$ & $122.7( \pm 9.40)$ & 0.62 \\
\hline & $\begin{array}{l}\text { Systolic After } \\
\text { Delivery }\end{array}$ & $122.97( \pm 7.30)$ & $123.14( \pm 9.21)$ & 0.83 \\
\hline & $\begin{array}{c}\text { Diastolic Before } \\
\text { Delivery }\end{array}$ & $78.38(+5.55)$ & $78.73(+5.78)$ & 0.53 \\
\hline & $\begin{array}{c}\text { Diastolic After } \\
\text { Delivery }\end{array}$ & $79.04( \pm 4.54)$ & $80.09( \pm 6.40)$ & 0.71 \\
\hline
\end{tabular}

Table 3. Distribution of Cases According to Side Effects

\begin{tabular}{|ccccc|}
\hline \multirow{2}{*}{ Side Effects } & \multicolumn{2}{c}{ Group A } & \multicolumn{2}{c|}{ Group B } \\
& No. & \%age & No. & \%age \\
Vomiting & 0 & 0 & 0 & 0 \\
Diarrhea & 8 & 4 & 2 & 1 \\
Shivering & 33 & 16.5 & 13 & 6.5 \\
Pyrexia & 7 & 3.5 & 0 & 0 \\
\hline
\end{tabular}

$\left(\chi^{2}=20.51\right) ;(\mathrm{P}=0.001)$ 
2). The incidence of side effects was higher when misoprostol was given. Shivering was the main side effect in $33(16.5 \%$, Table 3$)$ patients in misoprostol group. Incidence of side effects was more than double in group $\mathrm{A}$ as compared to group $\mathrm{B}(\mathrm{P}=0.0001)$ (Table 3).

\section{Discussion}

Third stage of labour is known to have unexpected morbidity and mortality mainly due to postpartum hemorrhage. About 1, 00,000 women die due to postpartum hemorrhage annually globally. It is the leading cause of maternal mortality in India, accounting $25-30 \%$ of all maternal death. Inspite of using oxytocics, postpartum hemorrhage is responsible for $50 \%$ of all hemorrhagic deaths and out of these, $80 \%$ are due to atonicity of uterus which is dramatic catastrophe and kills swiftly. ${ }^{9}$ Atonicity of uterus is preventable in majority of cases. A joint statement issued by the International Federation of Gynecologists and Obstetricians (FIGO) and International Confederations of Midwives (ICM) identifies the reduction of postpartum hemorrhage as a key component of safe motherhood. ${ }^{10}$ Our study was done to compare the safety and effectiveness of rectal misoprostol and intramuscular oxytocin for the prevention of PPH.

Traditionally, third stage of labour greater than 30 minutes has been considered abnormal and has warranted immediate intervention in form of manual extraction of the placenta. Active management of the third stage of labour is associated with less blood loss; however, it has more unpleasant side effects such as nausea, and pain as well as potential increased blood pressure when ergometrines are used. The average length of the third stage of labour was prolonged in the passive compared with the active management group and in those whose third stage of labour exceeded 30 minutes. ${ }^{11}$ The length of the third stage of labour is correlated well with postpartum hemorrhage. A third stage of labour longer than 18 minutes is associated with a significant risk of PPH. After 30 minutes, the odds of having PPH are 6 times higher than before 30 minutes. ${ }^{12}$ In our study, mean duration of third stage of labour was $12.96( \pm 4.33)$ minutes in group $A$ and $13.51( \pm 4.53)$ minutes in group B with no statistical significant difference $(\mathrm{P}=0.22)$ in consonance with study by Bugalho A et al $(2001)^{13}$, Karkanis SG et al $(2002)^{14}$. Placenta was not retained in any of the groups. Mean blood loss in group A was $128.10( \pm 41.88)$ $\mathrm{ml}$ and in group B was $123.92( \pm 37.07) \mathrm{ml}$. This can be explained from the pharmacokinetics of misoprostol as rectal route has slow uptake but prolonged duration. No patient in both the groups had PPH as defined quantitatively by blood loss of $\geq 500 \mathrm{ml}$ and clinically also. No statistical significant difference was observed between the two groups in amount of blood loss as observed in the studies conducted by Bambigboye et al $(1998)^{15}$, Diab KM et al (1999) $)^{16}$. Our observation was not in accordance with the study conducted by Gerstenfeld TS $(2001)^{17}$ where they took patients where labour was induced and/or augumented. They have not considered the possibility that induction and augmentation of labour with prostaglandins or oxytocin might negatively affect the efficacy of these drugs to halt PPH in these same labours. No statistical significant difference in mean hemoglobin concentration $(\mathrm{P}=0.74$, $0.92)$ and hematocrit value $(\mathrm{P}=0.63,0.08)$ before and after delivery was observed as evidenced in study conducted by Bugalho et al (2001).

There was statistical significant difference $(\mathrm{P}=0.0001)$ in the mean temperature after delivery (table 2). Our study depicted significantly higher mean temperature $\left(37.27 \pm 0.52^{\circ} \mathrm{C}\right)$ in group receiving misoprostol enema than in group receiving oxytocin $\left(36.93 \pm 0.19^{\circ} \mathrm{C}\right)$ in consonance with other studies ${ }^{18,14}$. Like other prostaglandins, misoprostol has also common adverse effects like nausea, vomiting, abdominal pain, chills, shivering and fever which are dose dependent. Pyrexia is centrally mediated prostaglandin $\mathrm{E}_{1}$ effect. In various clinical trials, the increase in temperature after the administration of misoprostol is a relatively common finding. ${ }^{18,19}$ Usually gastrointestinal side effects are more when misoprostol is given orally. As in our study, misoprostol was given rectally, so incidence was low. Patients in both the groups did not require additional oxytocics, blood requisition and blood transfusion.

As all uterotonics, except misoprostol, require parenteral administration. The main interest in trying to substitute the intramuscular injection of oxytocin with the rectal administration of misoprostol is to avoid the use of needles which is most relevant in countries like India with high incidence of hepatitis B, C and HIV. Misoprostol has great potential in preventing PPH. Misoprostol, because of low cost, stability and ease of administration, would be a boon in third world countries where hemorrhage remains a major cause of maternal mortality irrespective of minor side effects.

\section{References}

1. Berg CJ, Atrash HK, Koocnin LM. Pregnancy related mortality in the United States. American Journal of Obstet \& Gynaecol 1996; 88: 161-167.

2. Edwin Chandraharan, Sabaratnam Arulkumaran. Management Algorithm for Atonic Postpstpartum hemorrhage. Journal of Paediatrics, Obstetrics \& Gynaecology May/June 2005; Vol. 31, No. 3: 106112.

3. Prendiville W, Elbourne D, Chalmers I. The effects of routine oxytocin administration in the management of third stage of labour: an overview 
of the evidence from controlled trial. British Journal of Obstet \& Gynaecol 1988; 95: 3-16.

4. McDonald SJ, Prendiville WJ, Blair E. Randomized controlled trial of oxytocin alone versus oxytocin and ergometrine in active management of the third stage of labour. BMJ 1993; 307: 1167-1171.

5. Mercer JS. Current best evidence: A review of the literature on umbilical cord clamping. J Midwifery Women's Health 2001; 46: 402-14.

6. Elbourne DR, Carroli G, Wood J et al. Prophylactic use of oxytocin in the third stage of labour (Systematic review), Vol. 3: 2005.

7. El-Rafaey H, Rodeck C et al. Misoprostol for third stage of labour. Lancet 1996; 347: 1257.

8. Lumbiganon P, Villar J, Carroli G et al. Side effects of oral misoprostol during the first 24 hours after administration in the third stage of labour. BJOG 2002; 109: 1222-1226.

9. Arulkumaran S, Decruz B. Surgical management of severe postpartum hemorrhage. Curr Obstet Gynecol 1999; 9: 101-105.

10. Joint Statement: Management of the third stage of labour to prevent postpartum hemorrhage. J Midwifery Women's Health 2004; 49(1): 76-77.

11. Dombrowski MP, Bottoms SF, Hurd WW. Third stage of labour: analysis of duration and clinical practice. Am J Obstet Gynecol 1995; 172: 1279 1284.

12. Everett Magann, Sharon Evans, Sumeet $P$ et al. The length of the third stage of labour and risk of postpartum hemorrhage. Obstetric \& Gynecology 2005; 105: 290-293.
13. Bugalho A, Daniel A, Faudes A, Cunha M. Misoprostol for prevention of PPH. International Journal of Obstet \& Gynaecol 2001; 73: 1-6.

14. Karkanis SG, Caloia D, Salenieks ME et al. Randomized controlled trial of rectal misoprostol versus oxytocin in the third stage management. American Journal of Obstet \& Gynecol 2002 Feb; 24(2): 149-154.

15. Bamigboye AA, Justus G, Merrell DA et al. Randomized controlled trial of rectal misoprostol with syntometrine for management of third stage of labour. ACTA Obstet \& Gynaecol Scandinavian 1998; 77(2): 178-181.

16. Diab KM, Ramy AR. The use of rectal misoprostol as active pharmacological management of the third of labour. J Obstet Gynaecol Res 1999 Oct; 25(5): 327-332.

17. Gerstenfeld TS, Wing DA. Rectal misoprostol versus intravenous oxytocin for the prevention of PPH after vaginal delivery. American Journal of Obstet \& Gynecol 2001 October; 185(4): 878882 .

18. Amant F, Benard Spitz, Timmerman D et al. Misoprostol compared with methylergometrine for the prevention of PPH: a double blind randomized trial. British Journal of Obstet \& Gynecol 1999; 106: 1066-1070.

19. El-Refaey H, O'Brien, Walder J et al. Use of oral misoprostol in the prevention of PPH. British Journal of Obstet \& Gynaecol 1997; 104: 336-339. 